\title{
Optimization of Chitinase Production by Trichoderma virens in Solid State Fermentation Using Response Surface Methodology
}

\section{RACHMAWATY ${ }^{1, a^{*}}$, HALIFAH Pagarra ${ }^{1, b}$, HARTATII,c, ZULKIFLI Maulana $^{2, c}$ and MADIHAH Md. Salleh ${ }^{3, c}$}

\author{
${ }^{1}$ Biology Department, Mathematics and Natural Science Faculty, Universitas Negeri Makassar, \\ Indonesia
}

${ }^{2}$ Faculty of Agroculture, Universitas Bosowa, Indonesia
${ }^{3}$ Bioscience Department, Bioscience and Medical Engineering faculty, University Teknologi Malaysia

arachmawaty@unm.ac.id, bhalifah.pagarra@unm.ac.id, chartati@unm.ac.id

\begin{abstract}
Keywords: Chitinase, Trichoderma virens, response surface methodology, optimization, solid state fermentation.
\end{abstract}

\begin{abstract}
Physical factor for chitinase production by Trichoderma virens was first carried out using screening factor of 2-level factorial. The design was employed by selecting incubation time, temperature, moisture substrate, $\mathrm{pH}$, inoculums size and concentration ammonium sulphate as a model factor. The result of 2-level factorial design experiment showed thal all three independent variables have significant effect on chitinase production. The physical factor was further optimized using Central Composite Design in which response surface was generated later from the derived model. An experimental design of three variables including various incubation time, temperature and moisture substrate were created using Design Expert ${ }^{\circledR}$ Software, Version 6.0.4. The design consists of 20 experiments, which include 6 replicates at center points. The optimal value for each variable is incubation time sixth days, temperature $27.83^{\circ} \mathrm{C}$ and moisture substrate $54 \%$ with predicted chitinase activity of $0.48738 \mathrm{U} / \mathrm{g}$ of dry substrate. These predicted parameters were tested in the laboratory and the final chitinase activity obtained was $0.48864 \mathrm{U} / \mathrm{g}$ of dry substrate, which is similar to the predicted value. The obtained value of the chitinase production was $0.48738 \mathrm{U} / \mathrm{g}$ IDS, which was 1.2-fold higher than that of the 2-level factorial design $(0.261 \mathrm{U} / \mathrm{gds})$.
\end{abstract}

\section{Introduction}

Chitinases (E.C.3.2.1.14) are glycosyl hydrolases which catalyze the hydrolysis of insoluble chitin to its soluble derivatives. They are produced by various groupss of bacteria and fungi, and their physiological and ecological role vary with the source organism [15]. Neverletheless, the production of microbial extracellular chitinases has received much attention recently due to their potential applications in the reclamation of seafood processing crustacean bio-waste, producing of bio-active $N$-acetyl chitooligosaccharides, and production of GlcNAc [17]. In spite of such industrial, environmental, and biological significance, the high cost of the enzyme together with low activity and stability of available purified chitinases restrict its commercial exploitation [16].

Chitinase have shown an immense potential for increasing the production of several useful products in the most economic way [2]. Chitinases have many industrial and agricultural applications that require different types of preparations. The applications for chitinase are insect control, medical, biotechnology, biocontrol against phytopathogent and degrading of shell of sea waste.

Recent reports on the optimization of chitinase production focused on the conventional method of optimizing one-factor-at-a-time (OFAT). However, this method is not very much preferred as numerous potential influential factors may be involved and their interactions could be missed [14]. This method is simple, but it is laborious and time consuming if there are lots of factors to be determined [11]. 
An alternative and more approach is the use of statistical method, response surface methodology (RSM). Response Surface Methodology (RSM), a collection of mathematical and statistical techniques for building empirical models, is gaining importance for optimizing conditions for the production of industrially important products such as chemicals and enzymes [2]. RSM approach for analyzing the effect of multiple variables or factors, alone or in combination, on the process and generates a mathematical model that accurately describes the overall process [5]. RSM can be used to optimized the production of chitinases in the shrimp waste substrate.

A central composite design (CCD) was employed in this study for optimization process of chitinase production. CCD would develop a mathematical correlation model between the significant variables for chitinase production from $T$. virens [19]. CCD a well-established, widely used statistical technique for determining the influence of key factors by a small number of experiments [13]. This design has unique star or axial points $(\alpha)$, which means that the star points are of equal distance and radially distributed making the design rotatable or orthogonality, in order to fit the quadratic polynomials [18].

CCD has been succesfully applied to the optimization of medium components, an environmental factor for chitinase production [19], optimization of textile dye degradation by wet air oxidation [3], optimization of enzymatic hydrolysis conditions of steam-exploded corn stover [4] and analytical chemistry [1].

Preliminary studies have been carried out by looking at environmental factors that influence chitinase enzyme production using 2 factorial design factors (2LFD). The results of the study continued to optimize the production of chitinase using Central Composite Design (CCD) using factors that significantly affect chitinase production [11].

The purpose of the present work was to attempt to optimize all the physical parameters with statistical optimization strategy to increase the chitinase activity by Trichoderma virens under SSF conditions.

\section{Research Method}

\section{Materials}

Shrimp waste was kindly provided by the market local of Makassar, Indonesia. It contained 39,74\% protein, $23.08 \%$ chitin, $5.04 \%$ fat and $21.13 \%$ ash on a dry weight basis [15]. This material was dried in microwave for ten minutes until the weight constant and moisture content $(10 \%)$. Milled and stored in a dry place at room temperature. It was used as solid substrate for SSF without demineralization or deproteinization.

\section{Culture Condition}

T. virens was maintained on PDA. The spores were harvested from 7 days. Spores were suspended in $10 \mathrm{ml}$ of $1.0 \%(\mathrm{v} / \mathrm{v})$ Tween 80 aseptically. Spore suspension was then centrifuged at 4,000 rpm for $30 \mathrm{~min}$. The pellets formed were once again suspended in distilled water in order to prepare spore count suspension with $1 \times 10^{6}$ spores $/ \mathrm{ml}$ as an inoculums.

\section{Colloidal Chitin Preparation}

Chitin flakes from commercial crab chitin (Fluka) were used in the experiments. Twenty grams of commercial crab chitin were added to $200 \mathrm{ml}$ of concentrated hydrochloric acid, strirred with a glass rod at $40^{\circ} \mathrm{C}$ for $5 \mathrm{~min}$. Excess amount of distilled water was added and the gelatinous white material formed was washed with tap water until the filtrate $\mathrm{pH}$ reading falls between $\mathrm{pH}$ 6.5-7.0. The drained retentive is the colloidal chitin, which yields a soft pasty consistency with $98 \%$ moisture and stored at $4^{0} \mathrm{C}$ until further use [10]. 


\section{Production of Chitinase in SSF}

Five grams of dry shrimp shell contained in a $250 \mathrm{ml}$ Erlenmeyer flask and was supplemented with basal medium containing $0.17 \%\left(\mathrm{NH}_{4}\right)_{2} \mathrm{SO}_{4}, 0.025 \% \mathrm{MgSO}_{4} .7 \mathrm{H}_{2} \mathrm{O}, 0.028 \% \mathrm{KH}_{2} \mathrm{PO}_{4}, 0.007 \%$ $\mathrm{CaCl}_{2} \cdot 2 \mathrm{H}_{2} \mathrm{O}$. The initial $\mathrm{pH}$ substrate was adjusted 5.5. The thoroughly mixed substrate was autoclaved for $20 \mathrm{~min}$ at $121^{\circ} \mathrm{C}$ and cooled to room temperature before inoculation.

Under aseptic conditions, the sterilized solid substrates medium was inoculated with $10 \%(\mathrm{v} / \mathrm{v})$ of $1 \times 10^{6}$ spores $/ \mathrm{ml}$. Spore suspension was transferred into solid substrate medium, mixed thoroughly and the flasks were placed in an incubator at desired temperature and for desired time interval according to experimental design. All the sets were prepared in duplicate. Withdrawn samples were centrifuged at 4,000 rpm for $20 \mathrm{~min}$. The supernatant was used for chitinase assay and protein analysis [10].

\section{Chitinase Assay}

Chitinase activity was determined using $1.0 \%(\mathrm{w} / \mathrm{v})$ colloidal chitin as a substrate. One milliliter of supernatant was mixed with $1.0 \mathrm{ml}$ of $1.0 \%(\mathrm{w} / \mathrm{v})$ colloidal chitin in $1.5 \mathrm{M}$ citrate phosphate buffer, $\mathrm{pH}$ 5.0. The mixture was incubated at $50^{\circ} \mathrm{C}$ for $1 \mathrm{~h}$. the final product of reaction was determined using DNS method. One unit (U) of chitinase activity is defined as the amount of enzyme that is required to released of $1 \mu \mathrm{mol}$ of $\mathrm{N}$-acetyl-D-glucosamine per min under assay conditions.

\section{Experimental Design}

In this study, the levels of significant factors affecting chitinase production identified from 2-level factorial design were further optimized by using response surface methodology statistical design approach [11]. This part of research is to find the optimized condition to increase chitinase production. Design Expert Software version 6.0 was employed to study the effect of incubation time, temperature and moisture substrate during shrimp waste fermentation on optimization of chitinase by T.virens in solid state fermentation. Suitable range of each variable for the experiments was chosen by screening process.

Optimization of chitinase production by CCD using shrimp waste as a substrate was conducted by response surface methodology method. Three variables that had significant effect on chitinase production were determined using 2LFD, which were incubation time, temperature and moisture substrate. Experimental design was carried out using Design Expert ${ }^{\circledR}$ Software Version 6.0.4. It was found that three variables have significant effect on the chitinase production from T.virens in SSF, namely incubation time (A), temperature (B) and moisture substrate (C). Therefore, these three variables were studied in CCD in order to find the optimum conditions that can produce maximum amount of chitinase activity in SSF process. The coded levels $(-2,-1,0,1$, 2) are given in Table 1. In this study, a full composite design was selected with 14 star points and 6 replicates at center point, leading to a total of 20 experiments. The data obtained was fitted to a second-order polynomial equation as below

$Y=\beta_{0}+\sum \beta_{i} X_{i}+\sum \beta_{i i} X_{i i}+\sum \beta_{i j} X_{i} X_{k}$

Where $Y=$ predicted response for chitinase production, $\beta_{0}=$ constant, $\beta_{i}=$ linear effect, $\beta_{i i}=$ quadratic effect, $\beta_{i j}=$ interaction effect, $X=$ coded levels of the independent variables.

The design matrix for this experiment is as presented in Table 2. The significance of both and quadratic effects of three variables was evaluated by variance analysis (ANOVA). The three dimensional response surface were then plotted to find the effect of the independent variables on the response. The regression equation was solved using Design Expert ${ }^{\circledR}$ Software version 6.0.4. The statistical significance of the second order model equation was determined by a significant $\mathrm{F}$ - value and an insignificant lack-of fit F-value. The fit of the model was evaluated by the determination of $\mathrm{R}^{2}$ and adjusted $\mathrm{R}^{2}$ coefficient. 
Table 1. Coded and actual values of variables for optimization chitinase production of shrimp waste in solid state fermentation

\begin{tabular}{ccccccc}
\hline Variable & Component & -1 & 0 & 1 & 2 \\
\cline { 3 - 6 } A & Temperature & 15 & 20 & 25 & 30 & 35 \\
B & $\begin{array}{c}\left({ }^{0} \mathrm{C}\right) \\
\text { Incubation time } \\
\text { (days) }\end{array}$ & 3 & 4 & 5 & 6 & 7 \\
$\mathbf{C}$ & $\begin{array}{c}\text { Moisture } \\
\text { substrate (\%) }\end{array}$ & 30 & 40 & 50 & 60 & 70 \\
\hline
\end{tabular}

The validation of the model optimum value of selected variables was obtained by solving the regression equation using Design Expert software version 6.0.4. The predicted optimum value was confirmed by the experiment using the selected optimum values of the three variables.

Table 2. $2^{3}$ half fractional central composite design matrix employed for optimization of chitinase production of shrimp waste in SSF

\begin{tabular}{cccc}
\hline Experiment & & Variables (in coded value) & \\
\hline Run & A & B & C \\
\hline $\mathbf{1}$ & -1 & -1 & -1 \\
$\mathbf{2}$ & 1 & -1 & -1 \\
$\mathbf{3}$ & -1 & 1 & -1 \\
$\mathbf{4}$ & 1 & 1 & -1 \\
$\mathbf{5}$ & -1 & -1 & 1 \\
$\mathbf{6}$ & 1 & -1 & 1 \\
$\mathbf{7}$ & -1 & 1 & 1 \\
$\mathbf{8}$ & 1 & 1 & 1 \\
$\mathbf{9}$ & -2 & 0 & 0 \\
$\mathbf{1 0}$ & 2 & 0 & 0 \\
$\mathbf{1 1}$ & 0 & -2 & 0 \\
$\mathbf{1 2}$ & 0 & 2 & 0 \\
$\mathbf{1 3}$ & 0 & 0 & -2 \\
$\mathbf{1 4}$ & 0 & 0 & 2 \\
$\mathbf{1 5}$ & 0 & 0 & 0 \\
$\mathbf{1 6}$ & 0 & 0 & 0 \\
$\mathbf{1 7}$ & 0 & 0 & 0 \\
$\mathbf{1 8}$ & 0 & 0 & 0 \\
$\mathbf{1 9}$ & 0 & 0 & 0 \\
$\mathbf{2 0}$ & 0 & 0 & 0 \\
& 0 & & \\
\hline
\end{tabular}

\section{Result and Discussion}

\section{Central Composite Design (CCD)}

Based on the identification of variables by the screening factor using 2-level factorial design, followed by using CCD for optimization significant variables that affect to chitinase production. A CCD matrix was developed mathematical correlation model between significant variables for chitinase production by $T$. virens under solid state fermentation. With CCD, different combination of temperature, incubation time and moisture substrate are being experimented. To guard against systematic trends in uncontrollable variables, experimental run was randomized during the execution of the designed model [19]. 


\section{Model Development}

The data obtained was found to best fit the second-order polynomial compared to other polynomial models. Responses obtained from experiments were analyzed using analysis of variance (ANOVA). The regression equation obtained is as in equation 2 regardless of their significance. The generated equation is a second-order polynomial.

$$
\begin{aligned}
\mathrm{Y}(\mathrm{U} / \mathrm{g})= & 0.45+0.020 \mathrm{~A}+0.059 \mathrm{~B}-0.017 \mathrm{C}+0.006349 \mathrm{~A}^{2}-0.045 \mathrm{~B}^{2}-0.035 \mathrm{C}^{2} \\
& -\quad 0.029 \mathrm{AB}+0.016 \mathrm{AC}+0.051 \mathrm{BC}
\end{aligned}
$$

Where $\mathrm{Y}$ represent chitinase activity $(\mathrm{U} / \mathrm{g})$ while $\mathrm{A}, \mathrm{B}$, and $\mathrm{C}$ represents incubation time, temperature and moisture substrate respectively. This regression model was generated by Design Expert $^{\circledR}$ Software, after considering all the variables. It consists of 1 offset term, 3 linear terms, 3 quadratic terms and 3 interactions. The predicted levels of chitinase production obtained from chitinase activity of $T$. virens at each experimental point using equation 2 are shown in Table 3 along with experimental data.

Analysis of varians (ANOVA) for this model is presented in Table 4. The significant level for regression model was tested. It was found that the $P$-value obtained was 0.0001 , which is much smaller compared to the desired significant level of $p=0.05$. This indicates that the regression model was accurate in predicting pattern of significance for the chitinase production from T. virens. Regression coefficient $\mathrm{R}^{2}$ value of 0.9994 , suggest model adequacy and shows that the model is workable and can be accepted. The $\mathrm{R}^{2}$ value of 0.9994 was in good agreement with the adjusted $\mathrm{R}^{2}$ value of 0.9989 the optimal levels of variables were determined by constructing three dimensional surface plots according to the equations. The plots represent interaction of two variables while keeping others constant. The three dimensional surface plots of important variables have been elucidated. Contour plot and response surface plot (Figure 1 to 3 ) were generated based on equation 2.

Table 3. Regression analysis (ANOVA) for the production of chitinase by CCD

\begin{tabular}{ccccccc}
\hline Source & $\begin{array}{c}\text { Sum of } \\
\text { squares }\end{array}$ & $\begin{array}{c}\text { Degree of } \\
\text { freedom }\end{array}$ & $\begin{array}{c}\text { Mean } \\
\text { square }\end{array}$ & $\boldsymbol{F}$-value & $\mathbf{P}>\boldsymbol{F}$ & $\boldsymbol{R}^{\mathbf{2}}$ \\
\hline Model & 0.17 & 9 & 0.019 & $1995.22^{\mathrm{a}}$ & $<0.0001^{\mathrm{b}}$ & 0.9994 \\
\hline Residual & 0.00009638 & 10 & 0.00009638 & - & - & - \\
\hline Lack of fit & 0.00006916 & 5 & 0.00001383 & 2.54 & $0.1646^{\mathrm{c}}$ & - \\
\hline Pure error & 0.00002722 & 5 & $5.445 \mathrm{E}-06$ & - & - & - \\
\hline $\begin{array}{c}\text { Correlation } \\
\text { total }\end{array}$ & 0.17 & 19 & - & - & - & - \\
\hline
\end{tabular}

${ }^{a} F$-value is significant.

${ }^{\mathrm{b}}$ model is significant, with $\mathrm{P}>F$ less than 0.05

${ }^{c}$ model is fit due to insignificant $F$-value.

Standard deviation is 0.003105 
Table 4 Central composite design of variable (in coded levels) with experimental and the predicted values of chitinase activity

\begin{tabular}{cccccc}
\hline $\begin{array}{c}\text { Experiment } \\
\text { run }\end{array}$ & \multicolumn{2}{c}{ Variable (in coded value) } & \multicolumn{2}{c}{ Chitinase activity (U/g IDS) } \\
\hline $\mathbf{1}$ & $\mathrm{A}$ & $\mathrm{B}$ & $\mathrm{C}$ & Experiment & Predicted \\
\hline $\mathbf{2}$ & -1 & -1 & -1 & 0.356 & 0.36 \\
\hline $\mathbf{3}$ & 1 & -1 & -1 & 0.417 & 0.42 \\
\hline $\mathbf{4}$ & -1 & 1 & -1 & 0.427 & 0.43 \\
\hline $\mathbf{5}$ & 1 & 1 & -1 & 0.376 & 0.48 \\
\hline $\mathbf{6}$ & -1 & -1 & 1 & 0.188 & 0.19 \\
\hline $\mathbf{7}$ & 1 & -1 & 1 & 0.318 & 0.32 \\
\hline $\mathbf{8}$ & -1 & 1 & 1 & 0.467 & 0.47 \\
\hline $\mathbf{9}$ & 1 & 1 & 1 & 0.477 & 0.48 \\
\hline $\mathbf{1 0}$ & -2 & 0 & 0 & 0.437 & 0.44 \\
\hline $\mathbf{1 1}$ & 2 & 0 & 0 & 0.522 & 0.52 \\
\hline $\mathbf{1 2}$ & 0 & -2 & 0 & 0.158 & 0.16 \\
\hline $\mathbf{1 3}$ & 0 & 2 & 0 & 0.393 & 0.39 \\
\hline $\mathbf{1 4}$ & 0 & 0 & -2 & 0.351 & 0.35 \\
\hline $\mathbf{1 5}$ & 0 & 0 & 2 & 0.281 & 0.28 \\
\hline $\mathbf{1 6}$ & 0 & 0 & 0 & 0.451 & 0.45 \\
\hline $\mathbf{1 7}$ & 0 & 0 & 0 & 0.452 & 0.45 \\
\hline $\mathbf{1 8}$ & 0 & 0 & 0 & 0.452 & 0.45 \\
\hline $\mathbf{1 9}$ & 0 & 0 & 0 & 0.457 & 0.45 \\
\hline $\mathbf{2 0}$ & 0 & 0 & 0 & 0.451 & 0.45 \\
\hline & 0 & 0 & 0 & 0.454 & 0.45 \\
\hline
\end{tabular}

\section{Response Surface Plot}

Response surface methodology can be described as graphical representation of equations from data analysis. RSM allow calculation of maximum production based on a few sets of experiments, in which all factors were varied in a close range. It is a concise way of describing the behaveior of a system of variables. RSM is very useful in evaluating the significance of several factors especially that involves complex interactions. Complexity increases with number of variables [19]. Contour plot and response surface plot (Figure 1 to 3) were generated based on equation 2. The plot represent interaction of two variables while keeping other two constant.

Figure 1 shows the effect of incubation time and temperature with moisture substrate kept as constant at the center point values. Chitinase activity increased proportionally with increase in temperature from $20^{\circ} \mathrm{C}-30^{\circ} \mathrm{C}$. Temperature is one of the physical variables affecting SSF performance. Generally, the fungi can grow over a wide range of temperature from $20^{\circ} \mathrm{C}-55^{\circ} \mathrm{C}$ and the optimum temperature for growth could be different from that for product formation [15]. Suresh and Chandrasekaran (1998) reported that significant chitinase yield was obtained between the ranges of $22^{\circ} \mathrm{C}$ to $32^{\circ} \mathrm{C}$. Namphootiri et al [7] reported that Trichoderma harzianum exhibited a better growth as well as chitinase production at $30^{\circ} \mathrm{C}$.

It is a known phenomenon that increasing the temperature accelerates endothermic reactions. This is also true for chitinase production of chitinase waste material (Fereira et al., 2009). This positive influence by the temperature is, however reversed at much higher temperatures at which the enzyme is heat-denatured (Cheison et al., 2010) The present results would be applicable in the evaluated range of variables and in order to evaluate the product yield out of the range, further experimentation is required. Although incubation time has positive effect on chitinase production, its effect was neglible compared to temperature. The variation in the incubation time required for 
maximal chitinase production with the type of inoculum could be attributed to difference in the physiological conditions of the inoculum which consequently influenced the rate of growth and product formation of the fungus during SSF [15]. The growth rate of fungi and chitinase production pattern were generally dependent on the duration of incubation. The chitinase production start approximately from 20 to 40 hours during the exponential phase of growth [6]. The extended incubation time required for maximal chitinase production with shrimp waste maybe accounted for by its comparatively nutritionally inert and complex nature.

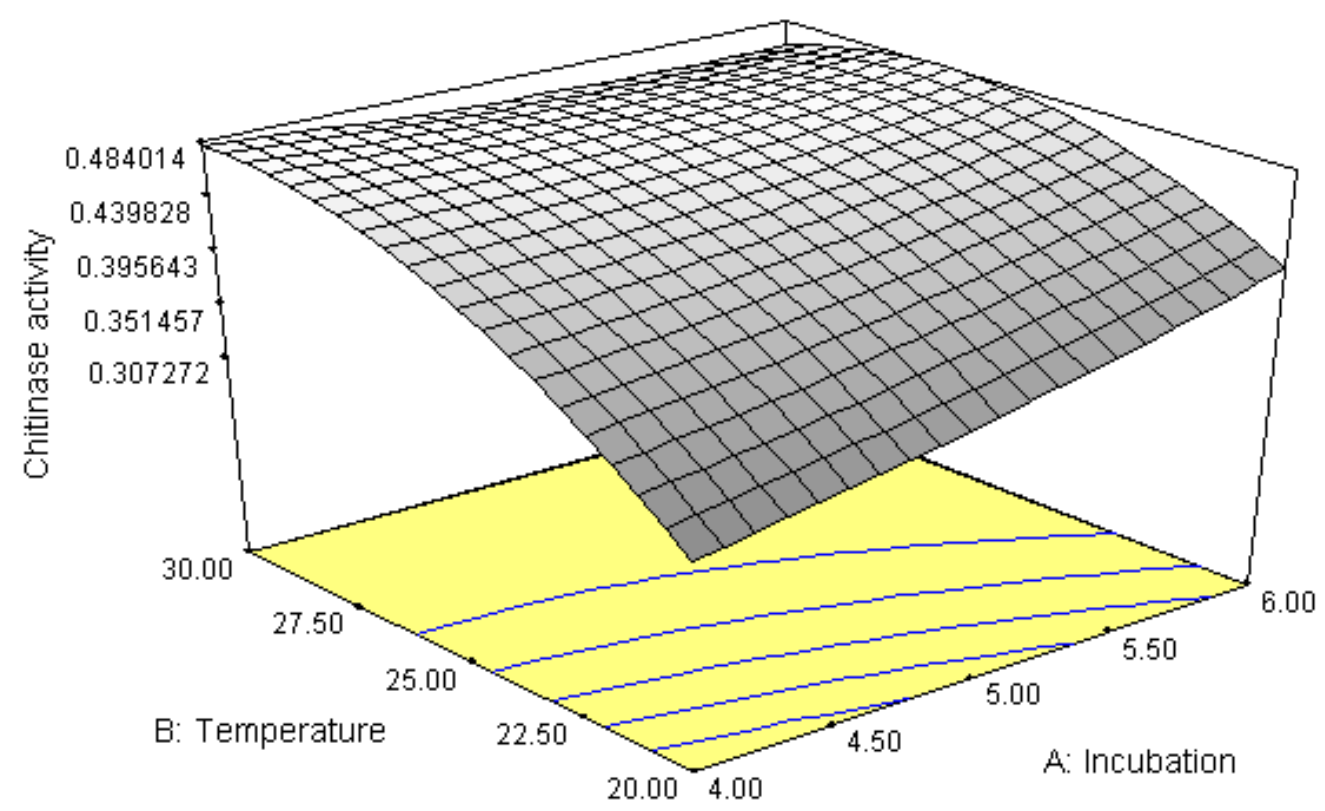

Figure 1. Response surface plot of chitinase activity from model equation: effect of incubation and temperature

Fig. 2 shows the chitinase activity was plotted as a function of incubation time and moisture substrate keeping the temperature constant. This equation does not show any interaction indicating that none of the variables have an interactive effect. Incubation time and moisture substrate had a quadratic response on chitinase production by $T$. virens where the response effect of incubation time was less significant as compared to moisture substrate. The moisture content in SSF is most important parameter [12]. Very high or very low levels of moisture substrate can reduce the chitinase production. The chitinase yield was lower when the substrate moisture was higher or lower than this level [2]. Here it was found that chitinase production increased as moisture content increased from $40 \%$ to $55 \%$. However, above $55 \%$ of moisture, there was steady decline in chitinase activity. The decrease in the chitinase activity with an increase in moisture might be attributed to the phenomenon of flooding of inter particle space of the substrate, which causes decreased porosity and lower oxygen transfer. Similarly, a moisture level lower than optimum leads to higher water tension. A lower degree of swelling, and the reduced solubility of nutrients of the solid substrate [6]. When water is made available in a lower or higher quantity than what is optimally required, the productivity of the process is significantly affected. Moisture optimization can be used to regulate and to modify the metabolic activity of the microorganism [12]. 


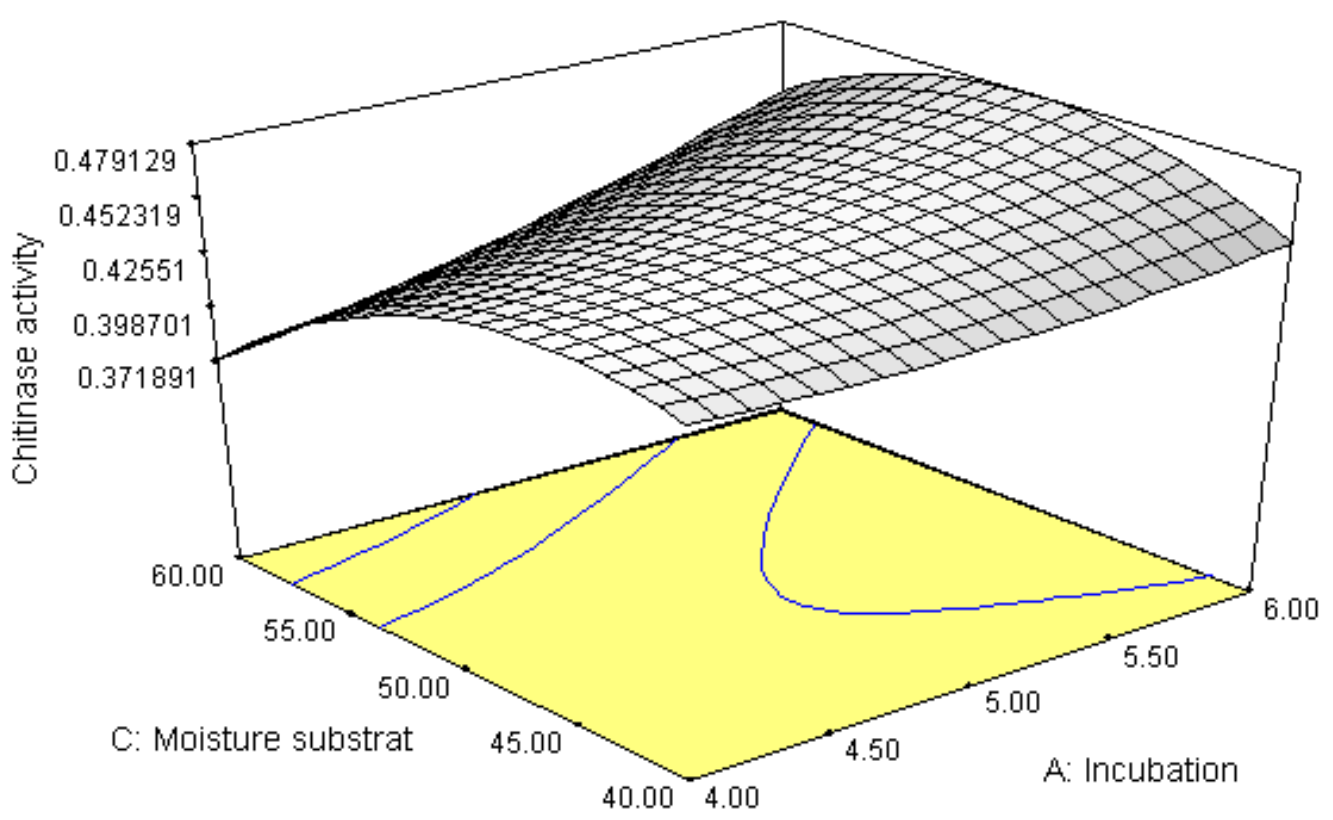

Figure 2. Response surface plot of chitinase activity from model equation : effect of incubation and moisture substrate

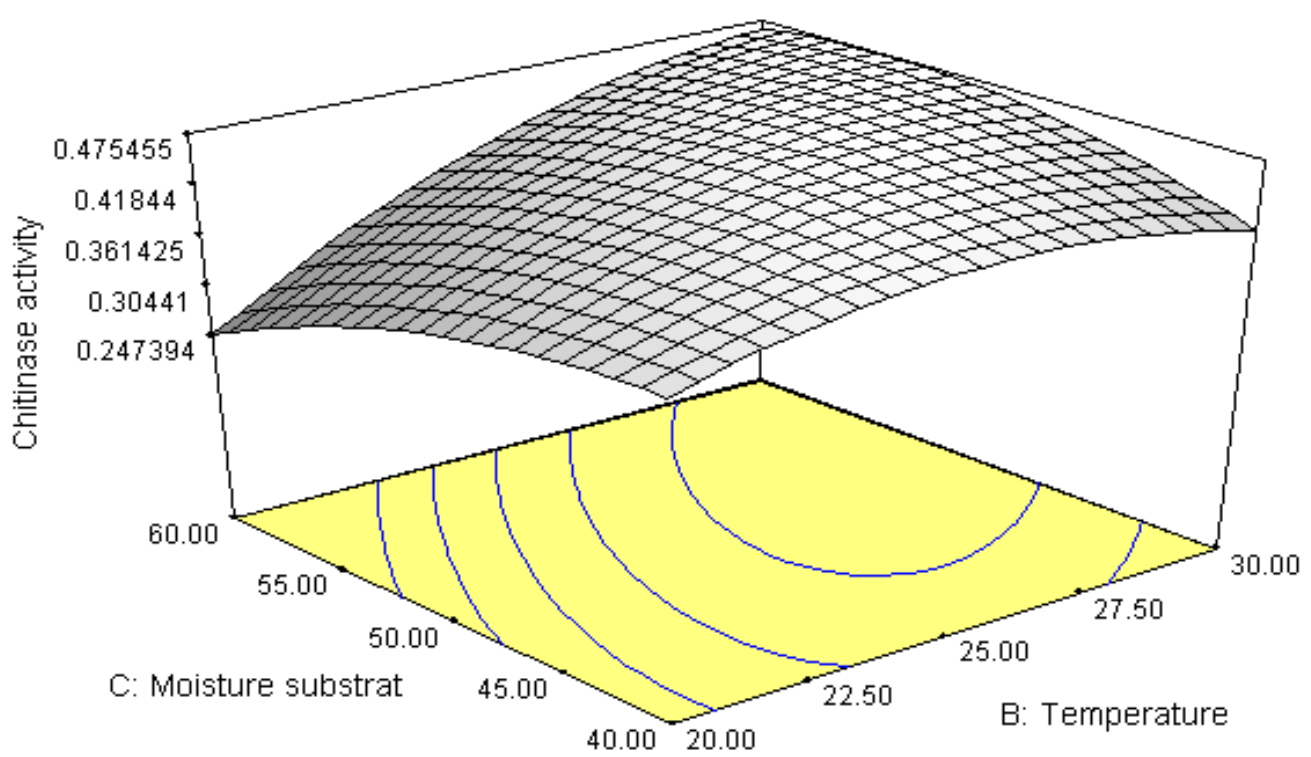

Figure 3. Response surface plot of chitinase activity from model equation : effect of temperature and moisture substrate

The effect of temperature and moisture substrate on chitinase production are shown in Fig. 3. The chitinase production was plotted as a function of temperature and moisture substrate, where both temperature and moisture substrate exerted a quadratic effect on chitinase production. The quadratic effect of moisture substrate was significant in comparison to effect of temperature. The incubation time was kept constant at the central point. For both the variables the chitinase production increase in a certain range and then falls at the extreme low or high levels. Moisture substrate in the range of $45 \%-55 \%$ can be expected to give a good chitinase production.

In general, each organism has its own requirement of special conditions for maximum enzyme production. Optimization by a conventional one-at-a-time approach leads to a substantial increase in enzyme production. However, this approach is not only cumbersome and time consuming, but also has the limitation of ignoring the importance of interaction of various physiological parameters. 
The statistical approach using RSM for process optimization serves the purpose by finding out the optimal condition in any given system by a set of independent variables over a specific region of interest by establishing the relation between more than one variable and a given response [8].

\section{Optimization and Validation of the Models}

Optimization of chitinase production in fermentation technology through statistical analysis of factorial design and response surface methodology (RSM) is common practice nowadays [19]. This technique has applied for the enhancement and optimization of culture conditions and medium component for various fermentation processes

The availability of the regression model (Eq. (2)) of the chitinase production by $T$. virens was tested using the calculated optimal culture composition, viz incubation time 6 days, temperature $27.82^{\circ} \mathrm{C}$ and moisture substrate $54.09 \%$. The obtained value of the chitinase production was $0.48738 \mathrm{U} / \mathrm{g}$ IDS, which agreed with the predicted value $(0.48864 \mathrm{U} / \mathrm{g}$ IDS) well, which was 1.2 fold higher than that of the 2-level factorial design $(0.261 \mathrm{U} / \mathrm{gds})$. Meanwhile, T. virens grows better in the statistically optimized conditions and the experimental result nearly similar to the predicted value which indicated the proficiency of the model for optimizing chitinase activity.

Adequacy of the model is important to check to ensure that it provides maximum approximation on the relation ship between factors and response. The residuals are an importanttool for judging the model adequacy [9]. Plotting the normal probability plot of residual can checked by normal probability (Figure 4). The normality assumption is satisfactory as normal residuals fall along a straight line. Plot of residuals versus the predicted response is shown in Figure 5. The residual plot indicates good prediction of maximum response along with constant variance and adequacy of the quadratic models because the model randomly distributed without any trends [9].

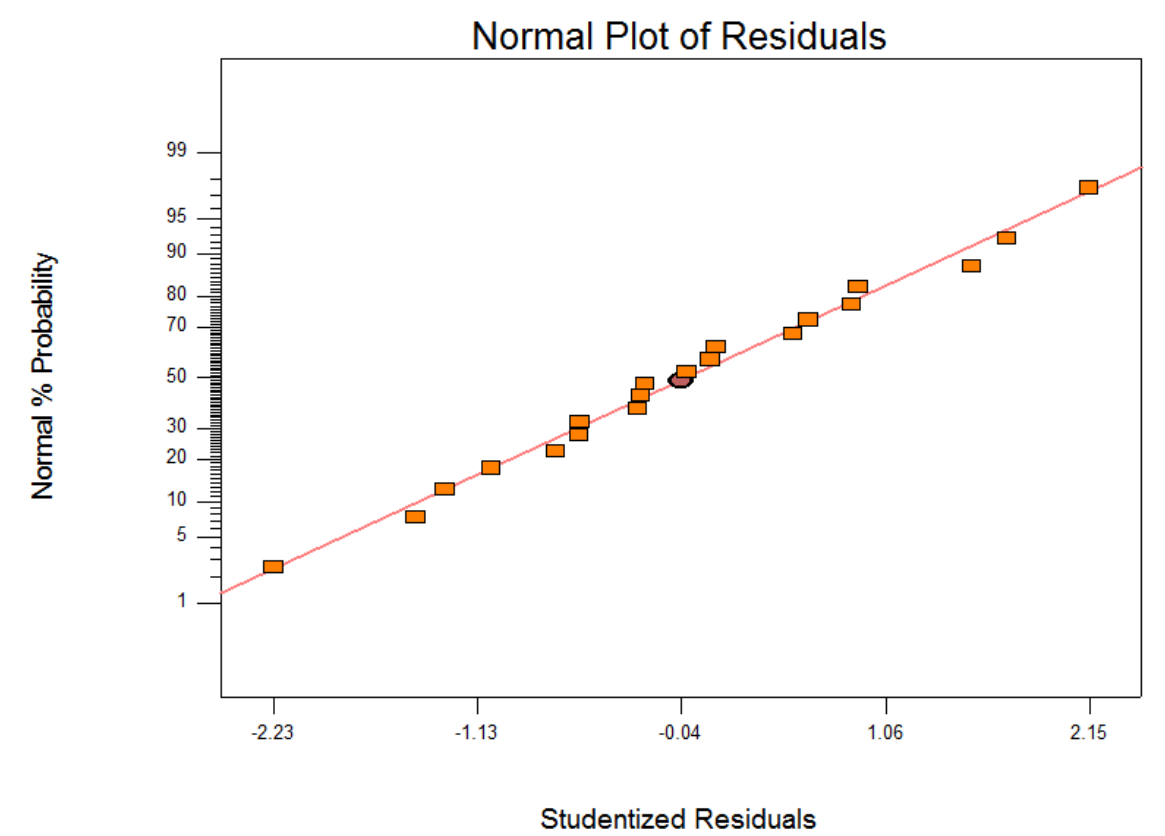

Figure 4. Normal probability of studentized residuals for chitinase production of shrimp waste 


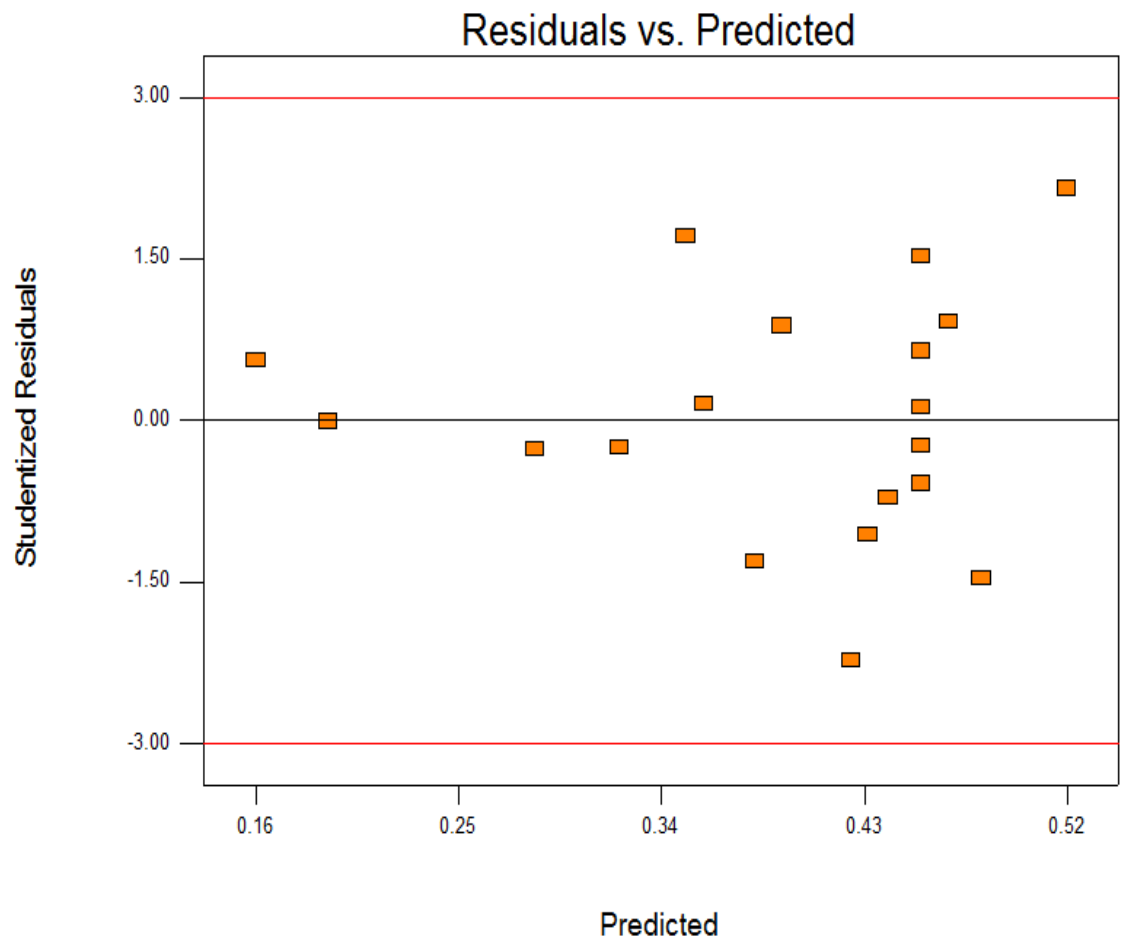

Figure 5. Plot of studentized residuals versus predicted response

\section{Summary}

Central composite design (CCD) is useful in determining and predicting the optimum level of a composition that gives significant influence for chitinase production. A fitted model shows suitable predition response that indicates improvement of a model. From the study, it was proven that moisture substrate in enhancement of chitinase activity. Increasing incubation time would help to increase chitinase activity. On the other hand, low temperature and high temperature can gave a bad effec towards chitinase activity.

\section{References}

[1] Bezerra, M. A., Santelli, R. E., Oliiveira, E.P., Villiar, L.S. and. Escaleira, L.A. (2008). Response surface methodology (RSM) as a tool for optimization in analytical chemistry. Talanta. 76: 965-977.

[2] Dahiya, N., Rupinder, T. and Gurinder Singh, H. (2006). Biotechnological aspects of chitinolytic enzymes: a review. Applied Microbiology and Biotechnology. 71: 773-782.

[3] Demirel, M. and Kayan, B. (2012). Application of response surface methodology and central composite design for the optimization of textile dye degradation by wet air oxidation. International Journal of Industrial Chemistry. 3: 1-10.

[4] Fang, H., Zhao, C. and Song, X.Y (2010). Optimization of Enzymatic Hydrolysis of Steam Exploded Corn Stover by Two Approaches: Response Surface Methodology or Using Cellulase From Mixed Cultures of Trichoderma reesei RUT-C30 and Aspergillus niger NL02. Bioresource Technology. 101: 4111-4119.

[5] Guerarda, F., Sumaya-Martinez, M.T., Laroque, D., Chabeauda, A. and Dufosse, L. (2007). Optimization of free radical scavenging activity by response surface methodology in the hydrolysis of shrimp processing discards. Process Biochemistry. 42: 1486-1491.

[6] Matsumoto K. S. (2006). Fungal Chitinases. Advances in Agricultural and Food Biotechnology Trivandrum, India. 
[7] Nampoothiri, M., Baiju, T.V., Sandhya, C., Sabu, A., Szakacs, G., Pandey, A., 2004. Process optimization for antifungal chitinase production by Trichoderma harzianum. J. Process Biochemistry 39 : 1583-1590.

[8] Nawani, N. N. and Kapadnis B. P. (2005). Optimization of chitinase production using statistics based experimental designs. Process Biochemistry. 40: 651-660.

[9] Qi, B., Chen, X., Fei Shen, Yi Su and Yinhua Wan (2009). Optimization of Enzymatic Hydrolysis of Wheat Straw Pretreated by Alkaline Peroxide Using Response Surface Methodology. Industrial and Engineering Chemical Resource. 48: 7346-7353.

[10] Rachmawaty and Madihah, M.S., 2014. Effect of Physical Pretreatment on Shrimp Waste for The Chitinase Production Under Solid State Fermentation by Trihoderma virens. Jurnal Teknologi Malaysia. 69 : 91-94.

[11] Rachmawaty, Syamsiah, Irma, I., Halifah, P., Hartati and Madihah, M.S. 2018. Screening Factors Influencing Chitinase Production by Trihoderma virens Using Two Level Factorial Design. International Conference Green Material, 29-10 April 2018, Ho Chi Mint City, Vietnam

[12] Shailes, R. W., Swaroop, S.K. and Jai, S.G. (2011). Chitinase Production in Solid-State Fermentation from Oerskovia xanthineo lytica NCIM 2839 and Its Application in Fungal Protoplast Formation. Current Microbiology . 63: 295-299.

[13] Singh, V., Mahvish Khan, Saif Khan and Tripathi, C. K. M. (2009). Optimization of Actinomycin V production by Streptomyces triostinicus using artificial neural network and genetic algorithm. Applied Microbiology and Biotechnology. 82: 379-385.

[14] Sudhakar, P. and Nagarajan, P. (2011). Production of Chitinase by Solid State Fermentation from Serratia marcescens. International Journal of Chemical and Technology Research. 3: 590.

[15] Suresh, P. V. (2012). Biodegradation of shrimp processing bio-waste and concomitant production of chitinase enzyme and N-acetyl-D-glucosamine by marine bacteria: production and process optimization. World Journal Microbiology and Biotechnology. 28: 2945-2962

[16] Suresh, P. V. and Anil Kumar, P. K. (2012). Enhanced degradation of $\alpha$-chitin materials prepared from shrimp processing byproduct and production of $\mathrm{N}$-acetyl-D-glucosamine by thermoactive chitinases from soil mesophilic fungi. Biodegradation. 23: 597-607.

[17] Suresh, P. V., Anil Kumar, P.K. and Sachindra, N.M (2011). Thermoactive $\beta-N-$ acetylhexosaminidase production by a soil isolate of Penicillium monoverticillium CFR2 under solid state fermentation: parameter optimization and application for $\mathrm{N}$-acetyl chitooligosaccharides preparation from chitin. World Journal Microbiology and Biotechnology. 27: 1435-1447.

[18] Tarleya, C. R. T., Silveira, G., Lopes dos Santos, W., Matos, G.D., Erik G., Bezerra, M. A., Manuel M., Sérgio, L.C.F. (2009). Chemometric tools in electroanalytical chemistry: Methods for optimization based on factorial design and response surface methodology. Microchemical Journal. 92: $58-67$

[19] Wasli, A,S., Madihah, M.S., Suraini, A.A., Osman, H., Mahadi, N.M., 2009. Medium optimization for chitinase production from Trichoderma virens using central composite design. Biotechnology and Bioprocess Engineering 14 : 781-787 